\title{
REVIEW
}

\section{A Review of the Multilevel Slug Test for Characterizing Aquifer Heterogeneity}

\author{
Chia-Shyun Chen ${ }^{1,2, *}$, Yun-Chun Sie ${ }^{1}$, and Ya-Ting Lin ${ }^{1}$ \\ ${ }^{1}$ Graduate Institute of Applied Geology, National Central University, Jhongli, Taiwan \\ ${ }^{2}$ Graduate Institute of Geophysics, National Central University, Jhongli, Taiwan
}

Received 12 April 2011, accepted 3 October 2011

\begin{abstract}
All aquifers are heterogeneous to a certain degree. The spatial distribution of hydraulic conductivity $\mathrm{K}(\mathrm{x}, \mathrm{y}, \mathrm{z})$, or aquifer heterogeneity, significantly influences the groundwater flow movement and associated solute transport. Of particular importance in designing an in-situ remediation plan is a knowledge of low-K layers because they are less accessible to remedial agents and form a bottleneck in remediation. The characterization of aquifer heterogeneity is essential to the solution of many practical and scientific groundwater problems. This article reviews the field technique using the multilevel slug test (MLST), which determines a series of $\mathrm{K}$ estimates at depths of interest in a well by making use of a double-packer system. The K(z) obtained manifests the vertical variation of hydraulic conductivity in the vicinity of the test well, and the combination of $\mathrm{K}(\mathrm{z})$ from different wells gives rise to a three-dimensional description of $\mathrm{K}(\mathrm{x}, \mathrm{y}, \mathrm{z})$. The MLST response is rather sensitive to hydraulic conductivity variation; e.g., it is oscillatory for highly permeable conditions $\left(\mathrm{K}>5 \times 10^{-4} \mathrm{~m} \mathrm{~s}^{-1}\right)$ and a nonoscillatory for $\mathrm{K}<5 \times 10^{-4} \mathrm{~m} \mathrm{~s}^{-1}$. In this article we discuss the instrumentation of the double-packer system, the implementation of the depth-specific slug test, the data analysis methods for a spectrum of response characteristics usually observed in the field, and field applications of the MLST.
\end{abstract}

Key words: Heterogeneity, Multilevel slug test, Vertical variations, Hydraulic conductivity

Citation: Chen, C. S., Y. C. Sie, and Y. T. Lin, 2012: A review of the multilevel slug test for characterizing aquifer heterogeneity. Terr. Atmos. Ocean. Sci., 23, 131-143, doi: 10.3319/TAO.2011.10.03.01(Hy)

\section{INTRODUCTION}

All aquifers are heterogeneous to a certain degree as they are composed of geological materials of different hydraulic conductivities. The spatial variability of hydraulic conductivity in an aquifer, $\mathrm{K}(\mathrm{x}, \mathrm{y}, \mathrm{z})$, is usually referred to as aquifer heterogeneity, which significantly influences groundwater flow behavior as well as the underlying solute transport. Lack of information on $\mathrm{K}(\mathrm{x}, \mathrm{y}, \mathrm{z})$ can lead to an incomplete understanding of groundwater movement and thus a biased interpretation of plume migration. It is well recognized that the low-K layers in a contaminated aquifer are bottlenecks to many in-situ remediation measures. This is because they are able to store massive contaminants through molecular diffusion in the contamination stage that

\footnotetext{
* Corresponding author

E-mail: chenchia@ncu.edu.tw
}

can last decades. In the remediation stage, the low-K layers are much more difficult to clean up because they are less accessible to the remediation agents. As a result, a back diffusion process takes place to release the contaminants stored in the low-K layers into the surrounding high-K layers which are already decontaminated to a certain degree. This back diffusion process significantly prolongs the remediation duration and lowers remediation efficiency (e.g., see Bedient et al. 1999).

Moreover, it is well recognized that the heavy breakthrough tails normally observed in either laboratory or field tracer tests are largely controlled by back diffusion, and thus the influence of the low-K layers is a dominant factor underlying the non-Fickian transport phenomena (Haggerty and Gorelick 1995; Schumer et al. 2003; Zhang et al. 2008, 2009; Bianchi et al. 2011; and references given therein). 
How to characterize aquifer heterogeneity has been a major concern in hydrogeology and contaminant hydrogeology.

\subsection{An Overview of Relevant Field Technologies}

There are a few different field techniques available for the characterization of aquifer heterogeneity. These techniques are generally classified as the in-well method which is conducted in wells, or the out-well method which uses no wells. The most popular out-well method is the directpush technique. It employs a direct-push rig to drive into the aquifer the hydraulic profiling tool (HPT) which is able to continuously measure the electric conductivity distribution $\mathrm{Ec}(\mathrm{z})$, and the permeameter which is used to determine $\mathrm{K}$ values at a few different depths (Butler et al. 2007; Dietrich et al. 2008; Liu et al. 2009; and references given therein). A correlation for $\mathrm{Ec}(\mathrm{z})$ and the scattered $\mathrm{K}$ estimates yields a continuous distribution of $\mathrm{K}(\mathrm{z})$. The in-well method utilizes appropriate hydraulic test instruments in wells. There are three different in-well techniques which are frequently used: (1) the multilevel slug test (MLST) which is implemented with the aid of a double-packer system (e.g., Zlotnik and McGuire 1998a; Zlotnik and Zurbuchen 2003; Zemansky and McElwee 2005; Ross and McElwee 2007; Sie 2009; Alexander et al. 2011), (2) the dipole flow test (DFT) which is conducted with the aid of a triple-packer system with a pump submerged in between two lower packers (Zlotnik et al. 1997, 2001; Zlotnik and Zurbuchen 1998; Zurbuchen et al. 1998), and (3) a borehole flow meter test (BFT) which requires no packers but a borehole flowmeter (Boman et al. 1997; Arnold and Molz 2000; Crisman et al. 2001; Paradis et al. 2011).

Each of the in-well and out-well techniques has a range of conditions and purposes for which it is best suited. For example, the direct-push technique is only applicable to unconsolidated materials with a grain size ranging from 0.02 to $4 \mathrm{~mm}$. The maximum depth that the direct-push rig can reach is less than about $25 \sim 30 \mathrm{~m}$ due to a power limitation. Under these favorable conditions, the direct-push technique is rapid relative to in-well techniques. On the other hand, the applicability of three in-well techniques is largely affected by well conditions (e.g., well radius, well plumbness, screen length, the skin effects, and smoothness of the borehole surface or the well casing surface) instead of geological conditions. That is, they can be used in either wells in unconsolidated aquifers or open boreholes in fractured formations.

Regarding field applicability, the BFT is easiest to apply and the DFT is most difficult to use. Regarding the consistency of the test results, it was found in an alluvial aquifer that a strong correlation exists between the MLST and DFT, and a less strong correlation between the BFT and other two tests (Zlotnik and Zurbuchen 2003). Regarding the sensitivity to heterogeneity, the response of MLST has distinctive characteristics for hydraulic conductivity variations; i.e., an oscillatory response for highly permeable conditions $(K>5$ $\times 10^{-4} \mathrm{~m} \mathrm{~s}^{-1}$ ) and a nonoscillatory response for moderate to low hydraulic conductivity conditions $\left(\mathrm{K}<5 \times 10^{-4} \mathrm{~m} \mathrm{~s}^{-1}\right)$. Such a distinction is not available in the DFT and BFT.

\subsection{Scope and Purposes}

This article aims to review the MLST with an emphasis on its instrumentation, and implementation as well as the evolution of the relevant models and data analysis methods. In section 2, we discuss the double packer system and its implementation with an emphasis on the test initiation which is important to consequent data quality. In section 3, typical MLST responses are discussed, and their underlying influence addressed. In section 4, the evolution of modeling the MLST in the last decade is discussed, and in section 5, two methods of analyzing oscillatory and nonoscillatory responses are given in detail for practical purposes. Some field applications of the MLST and relevant data analyses are discussed in section 6. In section 7, conclusions and suggestions are given. All the field data used in this article are from MLSTs conducted at different aquifers in Taiwan, unless otherwise noted. All the wells used are $4 "$ in diameter $\left(r_{w}=0.051 \mathrm{~m}\right)$ and the riser pipe is $1 "$ in diameter $\left(r_{c}=0.014 \mathrm{~m}\right)$.

\section{INSTRUMENTATION AND IMPLEMENTATION OF MLST}

A slug test determines the $\mathrm{K}$ value for the geological materials immediately adjacent to the test section by analyzing the test response due to an initial pressure difference $\mathrm{w}_{0}$ between the well water and surrounding groundwater. The MLST is a series of depth-specific slug tests conducted at different depths in a well with the aid of a double-packer system. For each well, a profile of $\mathrm{K}\left(\mathrm{z}_{\mathrm{i}}\right)$ is obtained, where $z_{i}$ denotes the center depth of the test section of each slug test, and $\mathrm{i}=1,2,3, \ldots, \mathrm{n}$. For many wells, the combination of the $\mathrm{K}\left(\mathrm{z}_{\mathrm{i}}\right)$ of each well gives a three-dimensional description of aquifer heterogeneity. We will discuss the doublepacker system and the test initiation method to generate a stable $\mathrm{w}_{0}$, which influences the quality of the subsequent test response.

\subsection{The Double-Packer System}

As shown in Fig. 1, the most often used double-packer system consists of two pneumatic packers connected by a perforated stainless steel pipe (the test section) and a PVC riser pipe. The riser pipe extends the test section, through the inner channel of the top packer, to the ground surface. The length of the riser pipe can be adjusted to fit the depth of the double packer system in the well. Inside the riser pipe there is a pressure transducer submerged at a depth, $\mathrm{D}_{\mathrm{T}}$, to measure the pressure head change, $\mathrm{H}(\mathrm{t})$, of the water col- 


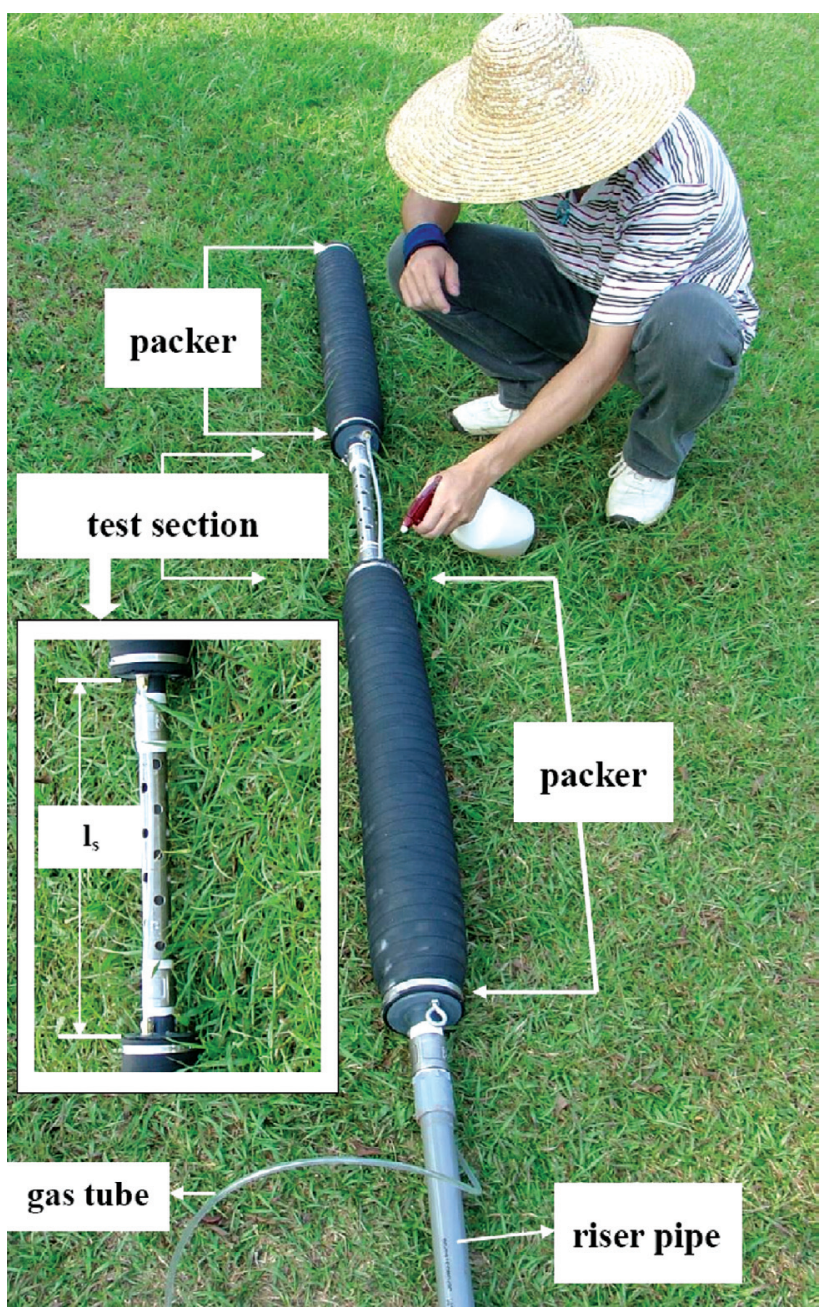

Fig. 1. The double packer system consists of two pneumatic packers connected by a test section and a riser pipe. The gas tube is used to inflate or deflate the packers.

umn above $\mathrm{D}_{\mathrm{T}}$. Radius of the riser pipe, $\mathrm{r}_{\mathrm{c}}$, therefore must be large enough to host the pressure transducer. The test section radius $r_{s}$, usually $0.0127 \mathrm{~m}(0.5 \mathrm{inch})$, has little influence on the MLST response. The test section length, $1_{s}$, however, significantly affects the resolution of the test results; that is, the vertical average effect on the estimate of $\mathrm{K}$ is inversely related to the test section length (Zemansky and McElwee 2005; Sie 2009). Furthermore, Sie (2009) found that the MLST responses cease to change when $1_{\mathrm{s}}$ is less than about $0.41 \mathrm{~m}$ in a weakly heterogeneous alluvial sandy aquifer. For highly heterogeneous conditions, this phenomenon has not been observed. A smaller $1_{s}$ normally results in less vertical average effect and allows more data points of the $\mathrm{K}$ estimates to be collected, thereby achieving a higher resolution for $\mathrm{K}\left(\mathrm{z}_{\mathrm{i}}\right)$. Using a large section length will not only cause an excessive vertical average effect, but also create technical difficulties in the field. For example, the total length of the double packer system alone can be easily over $3 \mathrm{~m}$ if $1_{\mathrm{s}}$ is longer than $1 \mathrm{~m}$. Such a long double-packer sys- tem is quite easy to break when it is being lowered down to the well. It is suggested that $l_{\mathrm{s}}$ be less than $1 \mathrm{~m}$.

The pneumatic packer is made of inflatable material with a length ranging from 0.3 to $1 \mathrm{~m}$, depending on the manufacturer. When deflated, the radius of the packer is smaller than the well radius, $r_{w}$, so the double-packer system can be freely lowered down to a depth of interest. Upon reaching this depth, the packers are inflated by a pressurized nitrogen cylinder at ground surface. Radius of the fully inflated packer becomes slightly greater than $r_{w}$, and thus the inflated packers are able to seal off the surrounding well screen while holding the double-packer system in place (Fig. 2). The two inflated packers effectively isolate the test section from the rest of the well, so groundwater can flow into or out of the riser pipe only through the test section. A slug test is performed and $\mathrm{H}(\mathrm{t})$ measured. The temporal variation of $\mathrm{H}(\mathrm{t})$ is under the influence of the hydraulic properties of the geological materials and flow conditions immediately surrounding the test section. Analyzing $\mathrm{H}(\mathrm{t})$ with an appropriate method will yield an estimate of $\mathrm{K}$, which represents of a vertically averaged hydraulic conductivity over the test section length. Upon completing one slug test, the packers are deflated and the double-packer system

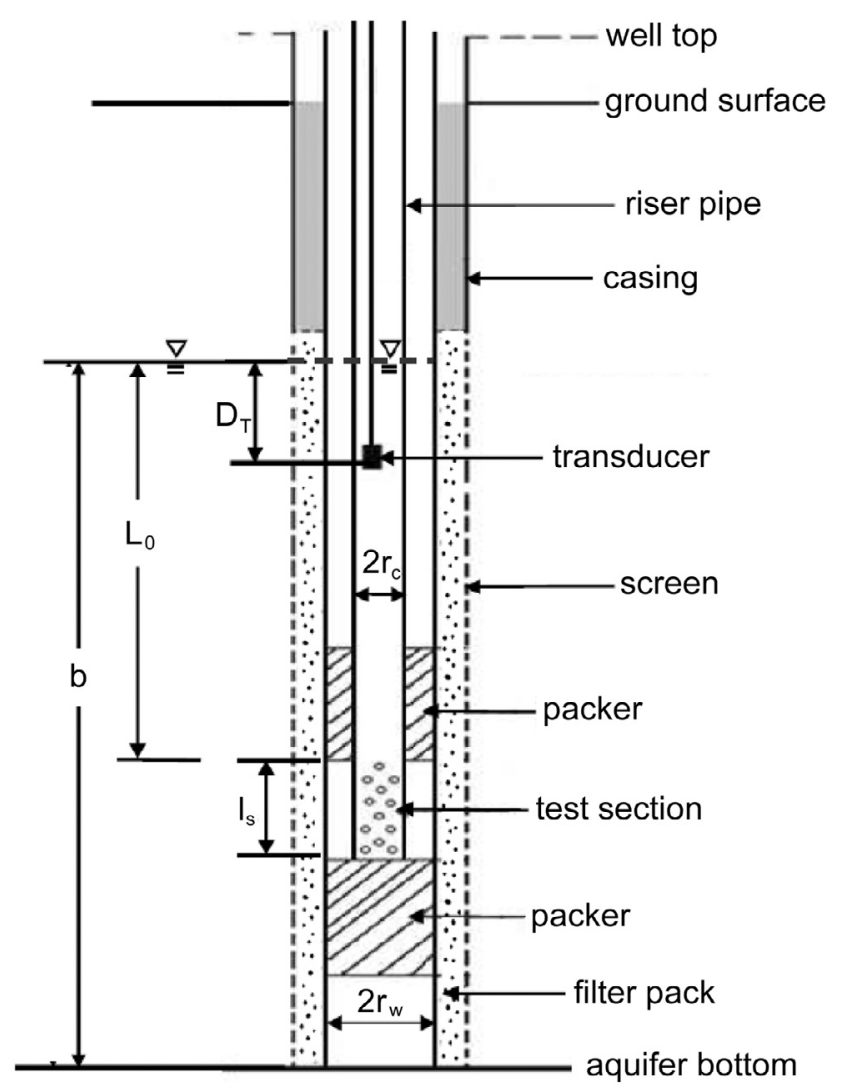

Fig. 2. Configuration of the MLST in a well. The double-packer system is fixed at a depth in the well screen section for a depth-specific slug test. The pressure transducer is placed inside the riser pipe at $\mathrm{D}_{T}$ below the initial water level. 
is lowered down for a new slug test. Repeating this procedure allows us to acquire a series of $\mathrm{H}(\mathrm{t})$ at different depths . A series of $\mathrm{K}\left(\mathrm{z}_{\mathrm{i}}\right)$ are obtained from $\mathrm{H}(\mathrm{t})$ of each depth.

The slug test hydraulically samples a support (or representative) volume which is considered to be a cylindrical volume of a depth equal to the screen length and a radius from the well surface into the aquifer. Beckie and Harvey (2002) found that the radius is inversely proportional to the square root of the storage coefficient. Guyonnet et al. (1993) approximate the possible radius of the support volume as $360 r_{w}$ for confined aquifers. For unconfined aquifers Bouwer and Rice (1976) gave empirical relationships approximating the radius of influence (see Appendix), which may be used to estimate the radius of the support volume for unconfined aquifers.

\subsection{Test Initiation}

The test initiation pertains to how to effectively create a pressure difference between the well water and surrounding groundwater. This step is important because it influences the quality of the consequential test response. Conventionally, a slug test is mechanically initiated with the dropping and removal of a solid object "slug" of some material within a well (Hvorslev 1951), or using a bailer to quickly extract or inject a certain amount of water into or from a well. These mechanical methods are difficult, and largely impractical, to create a stable initial water level change in the well, especially in highly permeable aquifers. An unstable water level makes the determination of the actual initial water level change $\mathrm{w}_{0}$ and the associated initial water velocity $\mathrm{dw} / \mathrm{dt}=\mathrm{v}_{0}$ very difficult. The knowledge of $\mathrm{W}_{0}$ is necessary in data analysis of both the oscillatory and nonoscillatory responses. The initial water velocity $\mathrm{v}_{0}$ is required as well for data analysis of an oscillatory response. Therefore, these mechanical test initiation methods are not recommended for use.

To avoid complications of an unstable initial water level, a pneumatic method was developed by Prosser (1981) which has been widely used to initiate a slug test (e.g., Butler 1998; Zemansky and McElwee 2005; Sei 2009 and others). It utilizes the same nitrogen cylinder that inflates the packers to depress the water level in the riser pipe to a displacement of $\mathrm{w}_{0}$. The pressure is held, usually less than 5 seconds, until the depressed water level becomes stable. This stable initial water level corresponds to an identifiable initial water level drop $\mathrm{w}_{0}$ and a zero water velocity, $\mathrm{v}_{0}=0$, effectively initiating the slug test with a known $\mathrm{w}_{0}$ and $\mathrm{v}_{0}$. (A zero initial water velocity is more desired than a non-zero initial water velocity in the data analysis, as discussed below.) Then the injected nitrogen is released and groundwater starts to flow into the test section, resulting in a recovery of the water level in the rise pipe. The pneumatic method is best for use in highly permeable aquifers. For conditions of moderate to low hydraulic conductivity, we found that it is as well effective (Sei 2009). To ensure that the pressure transducer is fully submerged during the test, $\mathrm{D}_{\mathrm{T}}$ must be greater than $\mathrm{w}_{0}$.

\section{CHARACTERISTICS OF MLST RESPONSE}

As mentioned above, the MLST response is oscillatory for highly permeable conditions $\left(\mathrm{K}>5 \times 10^{-4} \mathrm{~m} \mathrm{~s}^{-1}\right)$ and nonoscillatory for conditions of moderate to low hydraulic conductivity $\left(\mathrm{K}<5 \times 10^{-4} \mathrm{~m} \mathrm{~s}^{-1}\right)$. The measurement of oscillatory response is significantly influenced by the initial water displacement $\mathrm{w}_{0}$ and the depth of the pressure transducer, $\mathrm{D}_{\mathrm{T}}$.

\subsection{Oscillatory and Nonoscillatory Responses}

An oscillatory response is characterized by cyclic water level fluctuations around an initial water level position (Fig. 3), like medium to coarse sand. Such a highly permeable condition allows groundwater to rapidly flow into the test section. Consequently the water level in the riser pipe rises rapidly as well with significant acceleration. Due to the inertial force associated with the accelerating water movement, an uprising of the water level will not halt at the initial water level position but will pass over it until the inertial force is balanced by gravity and frictional losses. At this point the water level begins to fall, causing a fast drainage of water to the surrounding aquifer. Again due to the inertial force, the falling water level will stop at a certain depth below the initial water level position, at which the flow direc-

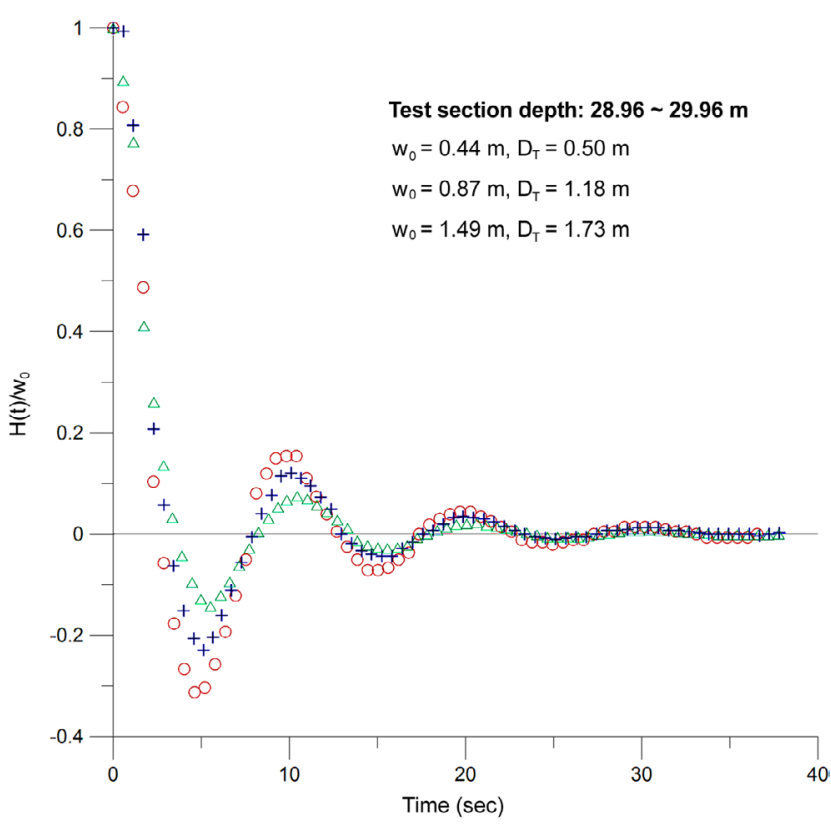

Fig. 3. Nonlinearity of $H(t)$ respect to $w_{0}$ is evidenced by the distinct normalized response of $\mathrm{H}(\mathrm{t}) / \mathrm{w}_{0}$ for different $\mathrm{w}_{0}$. 
tion is reversed and groundwater flows back into the riser pipe. Another rising cycle begins. After a few cycles of rise and fall, the water level will eventually stabilizes at the initial position.

A nonoscillatory response usually occurs when geological materials in the neighborhood of the test section is of medium to low hydraulic conductivity (e.g., $\mathrm{K}<5 \times$ $10^{-4} \mathrm{~m} \mathrm{~s}^{-1}$ ). Due to a relatively low $\mathrm{K}$, groundwater slowly flows into the test section after the riser pipe is depressurized. This slow movement results in a gradual recovery of the water level from $\mathrm{w}_{0}$ to the initial position. Variation of a nonoscillatory response usually exhibits a straight line on semilog paper, as shown in Fig. 4. The two sets of data were obtained from two MLSTs that were conducted consecutively at $29-30$ and $30-31 \mathrm{~m}$ in the same well in a sandstone aquifer. The test section length was fixed at $1_{\mathrm{s}}=$ $1 \mathrm{~m}$. Visual inspection of the core samples at the two depths (Fig. 4) indicates a fairly homogeneous condition with no visible fissures or abrupt changes in geological material; the discontinuities displayed resulted from the sample retrieval procedure at the site and are not natural fractures. This apparent homogeneity is confirmed by the coincidence of the two MLST responses shown in Fig. 4.

\subsection{Influence of $w_{0}$ and $D_{T}$}

In a static or slowly moving body of water, hydrostatic pressure prevails and is linearly proportional to $\mathrm{w}_{0}$. For a non-oscillatory response, therefore, $\mathrm{H}(\mathrm{t})$ measured is representative of $w(t)$ and can be directly applied to relevant models. The linearity of $\mathrm{w}(\mathrm{t})$ with respect to $\mathrm{w}_{0}$ is evidenced by the coincidence of the normalized responses of $\mathrm{w}(\mathrm{t}) / \mathrm{w}_{0}$ of various $\mathrm{w}_{0}$. That is, the MLST response can be repro- duced only when $w(t)$ is linear with respect to $w_{0}$.

Water pressure in an accelerating water column varies nonlinearly with depth. Field experiments indicate that the oscillatory $\mathrm{H}(\mathrm{t})$ is increasingly damped and shifted in phase as the transducer is submerged at a greater depth (Zurbuchen et al. 2002). Moreover, $\mathrm{H}(\mathrm{t})$ measured is different from $\mathrm{w}(\mathrm{t})$ (Springer 1991; Zurbuchen et al. 2002), and is nonlinearly proportional to $\mathrm{w}_{0}$, especially when $\mathrm{w}_{0}$ is relatively large (Butler et al. 1996; McElwee and Zenner 1998; Zurbuchen et al. 2002). The nonlinearity of $\mathrm{H}(\mathrm{t})$ with respect to $\mathrm{w}_{0}$ is evidenced by the distinct normalized responses of $\mathrm{H}(\mathrm{t}) / \mathrm{w}_{0}$ from three MLSTs (Fig. 3) using different $\mathrm{w}_{0}$ and $\mathrm{D}_{\mathrm{T}} ; \mathrm{w}_{0}=$ $0.44 \mathrm{~m}$ with $\mathrm{D}_{\mathrm{T}}=0.5 \mathrm{~m}, \mathrm{w}_{0}=0.87 \mathrm{~m}$ with $\mathrm{D}_{\mathrm{T}}=1.18 \mathrm{~m}$, and $\mathrm{w}_{0}=1.49 \mathrm{~m}$ with $\mathrm{D}_{\mathrm{T}}=1.73 \mathrm{~m}$. These three MLSTs were conducted in the same well in a fractured formation. The double-packer system was fixed at the depth from 28.96 $29.96 \mathrm{~m}\left(1_{\mathrm{s}}=1 \mathrm{~m}\right)$, where a fractured zone is identified.

The nonlinearity of $\mathrm{H}(\mathrm{t})$ with respect to $\mathrm{w}_{0}$ makes data analysis complicated, as will be discussed below. Nevertheless, this nonlinearity can be avoided when the MLST is performed following a specific operational guideline; whereby, the pressure transducer is placed about $0.5 \mathrm{~m}$ below the initial water level and $\mathrm{w}_{0}$ is set less than $0.5 \mathrm{~m}$ (Zurbuchen et al. 2002; Butler et al. 2003). Also, at least two tests should be conducted using two different values of $\mathrm{w}_{0}$, both less than $0.5 \mathrm{~m}$ to make sure that the MLST response is linear with respect to $\mathrm{w}_{0}$ (van der Kamp 1976; Butler 1998). This multiple test practice also serves the purpose of checking the accuracy of the MLST in terms of the data reproduction under the specified conditions. For aquifers of moderate to low hydraulic conductivity, it is also suggested that $\mathrm{w}_{0}$ be set less than $0.5 \mathrm{~m}$ in order to avoid excessive recovery time of $w(t)$.
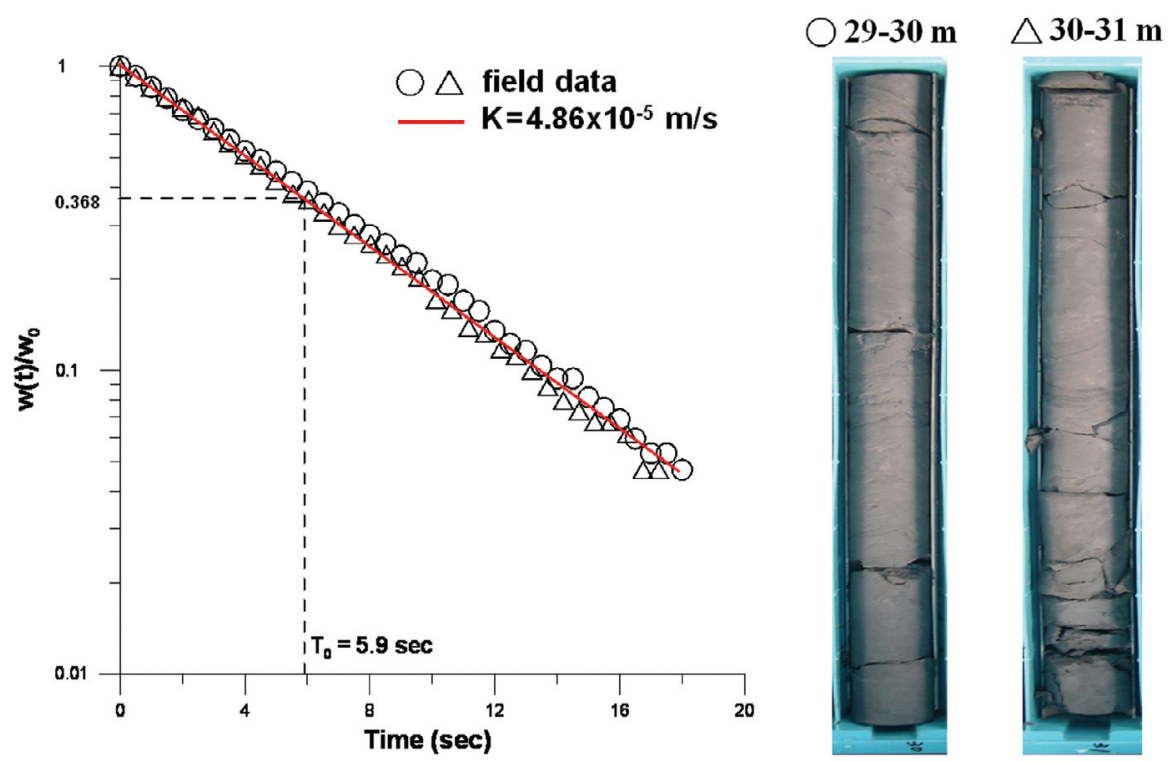

Fig. 4. Semilog plot of nonoscillatory responses from two MLSTs in a sandstone aquifer. The core samples show a relatively homogeneous condition; discontinuities are not natural fractures. 


\section{MODELS FOR MLST}

All slug test models are formulated in terms of the water level variation in the riser pipe, w(t) (Butler 1998). There are many models for a variety of slug test conditions, and we refer to Butler (1998) and Zurbuchen et al. (2002) for a comprehensive review. Herein we focus on the recent advancement of MLST models with regard to three important features, the shape factor, quasi-steady state approach, and linearity approach. Both the shape factor and the quasi-steady state approach were proposed by the first slug test model developed by Hvorslev (1951) which have been widely used in data analysis of slut tests and MLST. The nonlinear model is specifically developed to deal with an oscillatory response. Since $1_{s}$ is less than an aquifer thickness in each depth-specific slug test, the partial penetration effect on the groundwater flow field in the neighborhood of the test section is taken into account in all the MLST models.

\subsection{Shape Factors}

The first slug test model was developed by Hvorslev (1951), in which dimensional shape factors in [L] are used to account for the influences of the test section geometry on the flow field near the test section. The shape factor, $\mathrm{F}$ $=\mathrm{Q} / \mathrm{KH}$, is determined by approximating the cylindrical well screen as a fixed spheroidal equipotential. A total of nine different shape factors were given by Hvorslev (1951) (Fig. 2) for nine different flow conditions, respectively. The shape factor for the partially penetrating condition, $\mathrm{F}_{8}=2 \pi \mathrm{l}_{\mathrm{s}} / \ln \left(0.5 \alpha+\sqrt{1+0.25 \alpha^{2}}\right)$ with $\alpha=1_{\mathrm{s}} / \mathrm{r}_{\mathrm{w}}$ the aspect ratio, has been frequently used for the MLST. Because of the simplicity, the shape factors have been widely used in modeling slug tests under a variety of hydrogeological conditions in confined aquifers. The accuracy of the shape factors was challenged by Ratnam et al. (2001). Mathias and Butler (2006) found that $F_{8}$ is incorrect. However, the error reduces to only a few percentages when $\alpha$ is greater than about 3.0, which is usually encountered in the field. Therefore, the Hvorselev shape factors can be used to analyze MLST response in confined aquifers.

For unconfined aquifers, Bouwer and Rice (1976) gave empirical relationships for a dimensionless shape factor, $\mathrm{P}=\mathrm{Q} / 2 \pi \mathrm{Kl}_{\mathrm{s}} \mathrm{H}$. Note that $\mathrm{F}$ differs from $\mathrm{P}$ only by a factor of the test section length $1_{\mathrm{s}}$ which appears in the denominator of P while not in F. Recently, Zlotnik et al. (2010) employed an exact three-dimensional analytical solution to check the accuracy of the Bouwer and Rice empirical relationships. They found that the Bouwer and Rice shape factor and the exact solution are significantly different for the fully penetrating conditions, while agreeing well for partially penetrating conditions. For example, when $l_{s}=L_{0} / 15$, the relative difference between the Bouwer and Rice empirical relationship and the three-dimensional analytical solution is less than about $1 \sim 2$ percent for $\alpha>10$. For practical purposes, therefore, the Bouwer and Rice empirical relationship can be employed without introducing significant error when analyzing the MLST response in unconfined aquifers.

\subsection{Quasi-Steady State Approach}

The quasi-steady state approach calls for neglecting aquifer storage; e.g., the specific storage coefficient $S_{\mathrm{s}}$ in [L] can be set zero in modeling the groundwater flow induced by the test is significantly simplified. As a result, the model and hence the data analysis is significantly simplified. The appropriateness of the quasi-steady state approach has been studied by various authors. Chirlin (1989) noted that aquifer storage cannot be neglected for fully penetrating slug tests. Using the sensitivity analysis technique under various hydrogeological conditions; wherein, McElwee et al. (1995) for a homogeneous condition, Beckie and Harvey (2002) for a statistically heterogeneous system, and Audouin and Bodin (2008) for a fractured formation, it was found that the slug test response from a fully penetrating well is more sensitive to the variation of $\mathrm{K}$ than the variation of $\mathrm{S}_{\mathrm{s}}$ in the sense that a noun-unique combination of $\mathrm{K}$ and $\mathrm{S}_{\mathrm{s}}$ can be obtained for a set of measured slug test response. For partially penetration conditions however, this is not the case and a relatively unique $\mathrm{K}$ can be determined without $\mathrm{S}_{\mathrm{s}}$; that is, the quasi-steady state approach is valid. Hyder et al. (1994) found that aquifer storage can be neglected in low-K conditions for a broad range of the aspect ratio $\alpha$. Butler and Zhan (2004) found that aquifer storage in highly permeable aquifers can be neglected for $\alpha<130$. These criteria of neglecting aquifer storage are commonly satisfied in the field, and thus the quasi-steady state approach is reasonable for modeling the MLST responses. Of course, using the quasi-steady state model relinquishes the estimation of $\mathrm{S}_{\mathrm{s}}$, which is acceptable as the MLST aims to determine the $\mathrm{K}(\mathrm{z})$, instead of $\mathrm{S}_{\mathrm{s}}$.

\subsection{Nonlinearity and Linearity}

The hydrodynamics of oscillating water movement in the riser pipe makes the data analysis rather complicated because of two factors. First, the relevant models are inherently nonlinear with respect to w(t) (McElwee and Zenner 1998; Zurbuchen et al. 2002; Zemansky and McElwee 2005). Second, the measured $H(t)$ is not the same as $w(t)$, as discussed above. To the second point, the relationship for $\mathrm{H}(\mathrm{t})$ and $\mathrm{w}(\mathrm{t})$ is (Zurbuchen et al. 2002)

$H(t)=w(t)+\left[D_{T}+w(t)\right] w^{\prime \prime}(t) / g$

where $\mathrm{g}$ is the gravitational acceleration $\left(=9.8 \mathrm{~m}^{2} \mathrm{~s}^{-1}\right)$ and 
$w^{\prime \prime}(t)$ the second derivative of $w(t)$ standing for acceleration of the water level. It can be seen that $\mathrm{H}(\mathrm{t})$ is quite different from $w(t)$ if the water level acceleration is significant. Based on Eq. (1) and an appropriate nonlinear model, Zurbuchen et al. (2002) develop a data analysis method, which is not easy to use. Fortunately, the complications associated with hydrodynamic pressure can be avoided by using the aforementioned operational guideline wherein $\mathrm{w}_{0}$ is less than $0.5 \mathrm{~m}$ and $\mathrm{D}_{\mathrm{T}}$ is close to the initial water level. With such a small $\mathrm{w}_{0}$, acceleration of the water movement is significantly reduced and pressure head at shallow depth is close to $w(t)$. As shown by Eq. (1), when both $D_{T}$ and $w "(t)$ are small, $\mathrm{H}(\mathrm{t})$ is approximately equal to $\mathrm{w}(\mathrm{t})$, In this regard, a nonlinear model can correspondingly be linearized, and the associated data analysis becomes much simpler. It should be noted that the nonlinear model is also useful for certain cases where the oscillatory response is caused by some special well configurations; e.g., a well equipped with multiple concentric casing (Audouin and Bodin 2007) or a well with a bypass pipe (Zenner 2002).

\section{DATA ANALYSIS METHODS}

The methods discussed below cover a spectrum of frequently encountered nonoscillatory or oscillatory responses in terms of $\mathrm{w}(\mathrm{t})$. Therefore, it is reemphasized that conduction of the MLST follows the operational guideline stated above, whereby the measured $\mathrm{H}(\mathrm{t})$ is representative of $\mathrm{w}(\mathrm{t})$. Each method is discussed with an application to a field example.

\subsection{Data Analysis of Oscillatory Response}

For analyzing oscillatory responses, an analytical solution to a linear, quasi-steady state model (Springer and Gelhar 1991) is

$\frac{\mathrm{w}(\mathrm{t})}{\mathrm{w}_{0}}=\exp \left(-\frac{\beta \mathrm{t}}{2}\right)\left[\cos (\omega \mathrm{t})+\frac{\beta}{2 \omega} \sin (\omega \mathrm{t})\right]$

where $\omega=2 \pi / T$ is the oscillation frequency $\left[\mathrm{t}^{-1}\right]$ with $\mathrm{T}$ the period $[\mathrm{s}]$, and $\beta$ is the damping coefficient $\left[\mathrm{t}^{-1}\right]$. Based on Eq. (2), two curve matching methods were developed by Butler et al. (2003) and Chen and Wu (2006), respectively. Both methods are not effective in application because they require matching the data points to the type curves prepared using Eq. (2) through trial-and-error procedures. To eliminate the curve matching procedures, Chen (2006) developed an analytical method that takes advantage of pertinent mathematical characteristics of Eq. (2). Later Chen (2008) proves that this analytical method is also applicable to the oscillatory responses measured by pressure transducers placed at any depth in the well. That is, the restriction of
$\mathrm{D}_{\mathrm{T}}$ close to the initial water level set forth in the operational guideline can be relaxed when this method is used for data analysis. Ostendorf et al. (2005) also developed a closedform solution that is applicable for pressure transducer data from any depth in a well casing. However, its application to the evaluation of $\mathrm{K}$ is more complicated than the method of Chen (2006). Therefore, the analytical method followed by Chen (2006) is recommended for analyzing oscillatory response from the MLST.

It is known that hydraulic conductivity $\mathrm{K}$ is related to $\beta$ and $\omega$ through the following equation (Butler 1998; Chen 2006)

$K=\left(\frac{\omega^{2}+0.25 \beta^{2}}{\beta}\right) \frac{r_{c}^{2}}{r_{w}} F$

For confined aquifers, the dimensionless shape factor based on the Hvorslev's $F_{8}$ is (Butler 1998; Chen 2006)

$$
\mathrm{F}_{\mathrm{c}}=0.5 \alpha^{-1} \ln \left[0.5 \alpha+\sqrt{1+0.25 \alpha^{2}}\right]
$$

For unconfined aquifers, the dimensionless shape factor is (Butler 1998; Chen 2006)

$F_{u}=0.5 \alpha^{-1} \ln \left(R_{e} / r_{w}\right)$

where $R_{e}$ is the radius of influence that is dependent on the aspect ratio $\alpha$, the test section location, and some empirical coefficients for the water table effects. The determination of $\ln \left(\mathrm{R}_{\mathrm{e}} / \mathrm{r}_{\mathrm{w}}\right)$ is based on some lengthy empirical relationships, which are given in Appendix.

Either $\mathrm{F}_{\mathrm{c}}$ or $\mathrm{F}_{\mathrm{u}}$ can be evaluated a priori. The values of $\beta$ and $\omega$; however, need to be determined using pertinent characteristics exhibited by the MLST response. The main focus of the graphic data analysis method, therefore, is the evaluation of $\beta$ and $\omega$ from $w(t)$. The damping coefficient $\beta$ is related to the amplitude ratio of the oscillation (van der Kamp 1976; Chen 2006) as

$\beta=\frac{4}{T} \ln \left|\frac{\mathrm{H}_{k}}{\mathrm{H}_{\mathrm{k}+1}}\right|$

where $\mathrm{H}_{\mathrm{k}}, \mathrm{k}=1,2,3, \ldots$, is the $\mathrm{k}^{\text {th }}$ amplitude of oscillation occurring at $t_{k}, k=1,2,3, \ldots$ Based on Eq. (6), a graphic procedure is available for evaluating $\beta$ and $\omega$, and it is explained with the field data in Fig. 5. The MLST was conducted in a confined sandy aquifer with $1_{\mathrm{s}}=0.5 \mathrm{~m}$. The initial water level displacement is $0.45 \mathrm{~m}$, and the pressure transducer was placed at $D_{T}=0.5 \mathrm{~m}$. The value of $F_{c}$ calculated with Eq. (4) is 0.117 . The procedure of evaluating $\beta$ and $\omega$ is as follows. 


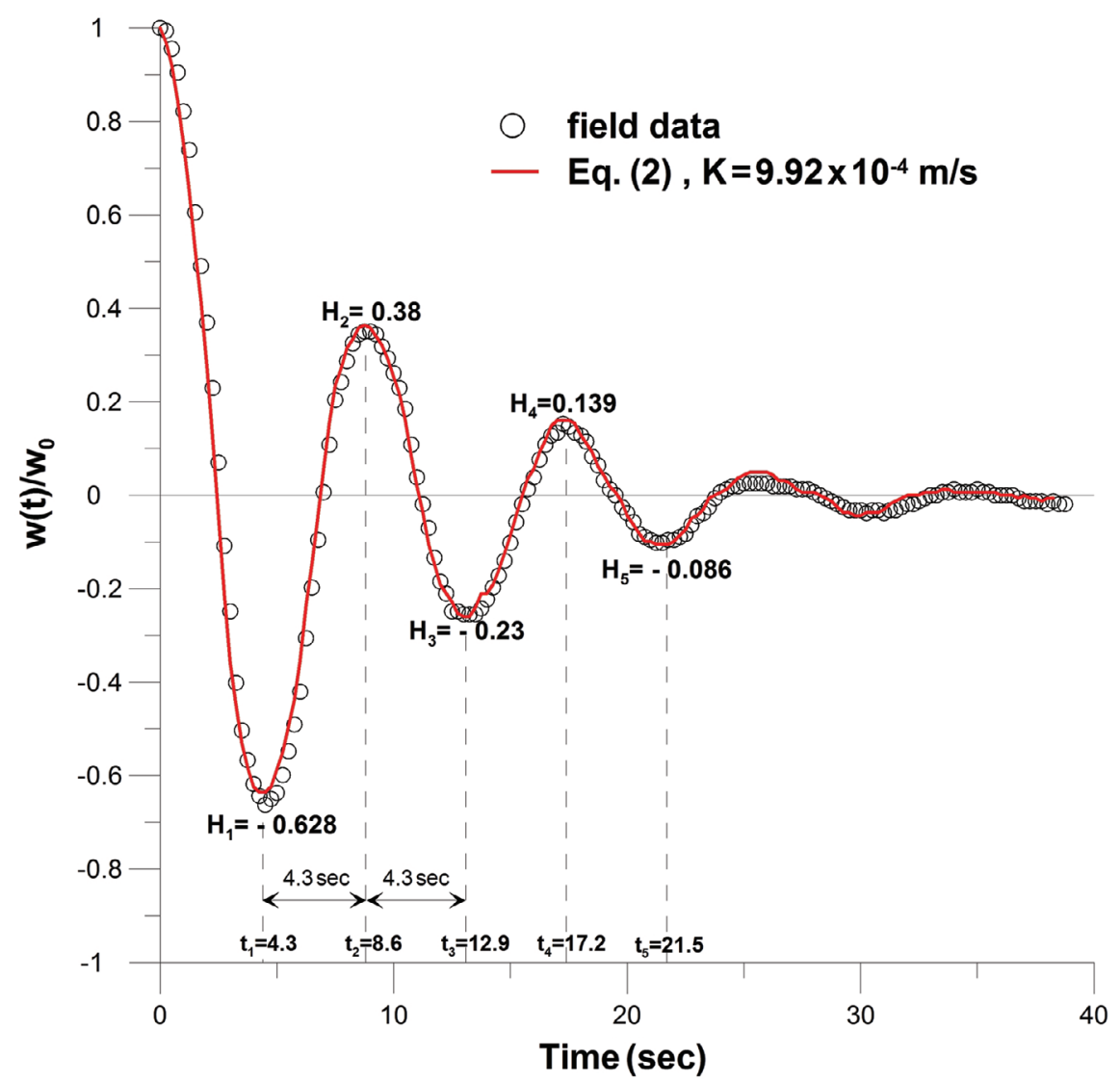

Fig. 5. Determination of the amplitude ratio and period for oscillatory response.

1. Plot the normalized response $\mathrm{w}(\mathrm{t}) / \mathrm{w}_{0}$ versus time, as shown in Fig. 5.

2. Determine $t_{k}$ of the discernable minimum or maximum points shown on the data plot. There are five such extreme points occurring at $\mathrm{t}_{1}=4.3 \mathrm{~s}, \mathrm{t}_{2}=8.6 \mathrm{~s}, \mathrm{t}_{3}=12.9 \mathrm{~s}$, $t_{4}=17.2 \mathrm{~s}$ and $t_{5}=21.5 \mathrm{~s}$. The period is determined as $\mathrm{T}=$ $t_{k+2}-t_{k}=8.6 \mathrm{~s}$, so the frequency is calculated as $\omega=2 \pi / T$ $=0.73 \mathrm{~s}^{-1}$. It should be noted that the maximum at $\mathrm{t}=$ 0 pertains to the initial water level displacement and is not considered as the first amplitude.

3. Determine the (normalized) amplitude $\mathrm{H}_{\mathrm{k}}$ of each $\mathrm{t}_{\mathrm{k}}$ : $\mathrm{H}_{1}=-0.628, \mathrm{H}_{2}=0.38, \mathrm{H}_{3}=-0.23, \mathrm{H}_{4}=0.139$ and $\mathrm{H}_{5}$ $=-0.086$. Apply all pairs of $\mathrm{H}_{\mathrm{k}}$ and $\mathrm{H}_{\mathrm{k}+1}$ to Eq. (6) to evaluate $\beta$. In theory the amplitude ratio $\left|\mathrm{H}_{k} / \mathrm{H}_{k+1}\right|$ is constant. However, the visual error in identifying $\mathrm{H}_{k}$ and $t_{k}$ as well as the measurement error of $\mathrm{H}(\mathrm{t})$ will result in different values for $\left|H_{k} / H_{k+1}\right|$. The average of the $\beta$ values obtained is taken as the estimate of $\beta$. For the field data, the four amplitude ratios are 1.653, $1.652,1.655$, and 1.616 , which respectively corresponds to $\beta=0.234,0.233,0.234$, and $0.223 \mathrm{~s}^{-1}$. So the average of the four $\beta$ values, $0.231 \mathrm{~s}^{-1}$, is taken as the estimate of $\beta$.

4. Use Eq. (3) to determine $\mathrm{K}$ with $\omega=0.73 \mathrm{~s}^{-1}, \beta=0.231 \mathrm{~s}^{-1}$ and $F_{c}=0.117$. The estimate of $\mathrm{K}$ is $9.92 \times 10^{-4} \mathrm{~m} \mathrm{~s}^{-1}$.

\subsection{Nonoscillatory Response}

The first slug test model was given by Hvorslev (1951) for low-K conditions in confined aquifers

$\ln \left[\frac{\mathrm{w}(\mathrm{t})}{\mathrm{w}_{0}}\right]=-\frac{\mathrm{Kr}_{\mathrm{w}}}{\mathrm{Fr}_{\mathrm{c}}^{2}} \mathrm{t}$

The data analysis of nonoscillatory response is based on Eq. (7), by which it is known that the normalized response on semilog paper will exhibit a declining straight line of a slope equal to - $\left(\mathrm{Kr}_{\mathrm{w}} / \mathrm{Fr}_{\mathrm{c}}^{2}\right)$. According to this characteristic, the first step of the data analysis is to plot the measured $\mathrm{w}(\mathrm{t}) /$ $\mathrm{w}_{0}$ on semilog paper, as shown in Fig. 4 . Then a straight line is plotted to fit most data points, and denote the time corresponding to $\mathrm{w}(\mathrm{t}) / \mathrm{w}_{0}=0.368$ as $\mathrm{T}_{0} ; \mathrm{T}_{0}=5.9 \mathrm{~s}$ in Fig. 4. It is straightforward enough to prove that $T_{0}$ is equal to the inverse of the slope of the fitted straight line, by noting $\ln (0.368)=-1$. As a result, $\mathrm{K}$ is determined as

$\mathrm{K}=\frac{\mathrm{F}_{\mathrm{c}}}{\mathrm{T}_{0}} \frac{\mathrm{r}_{\mathrm{c}}^{2}}{\mathrm{r}_{\mathrm{w}}}$

Accordingly, $\mathrm{K}$ is calculated to be $4.86 \times 10^{-5} \mathrm{~m} \mathrm{~s}^{-1}$, using $\mathrm{r}_{\mathrm{w}}$ $=0.051 \mathrm{~m}, \mathrm{r}_{\mathrm{c}}=0.014 \mathrm{~m}, \mathrm{~F}_{\mathrm{c}}=0.075$, and $\mathrm{T}_{0}=5.9 \mathrm{~s}$. 
Although the storage effect is largely negligible for $1_{\mathrm{s}}<130 \mathrm{r}_{\mathrm{w}}$, still it may impose an influence on the MLST response. When the storage effect is in effect, the MLST response is no longer a straight line but a concave downward curve, as shown in Fig. 6 where the MLST was conducted in a mudstone aquifer. Such a nonlinear characteristic is generally not observed under permeable conditions while it appears in aquifers of relatively hydraulic conductivity, as the storage effect is generally larger in fine materials than in coarse materials (Freeze and Cherry 1979). Because the aquifer storage effect is not negligible, the data analysis requires the use of a transient model, of which no simple graphic technique is available. A three-dimensional transient model, similar to the KGS model presented by Hyder et al. (1994), is employed with an automated least square regression algorithm to estimate $\mathrm{K}$ and $\mathrm{S}_{\mathrm{s}}$, the specific storage coefficient. The estimates obtained are $\mathrm{K}=1.48 \times 10^{-7} \mathrm{~m} \mathrm{~s}^{-1}$ and $S_{\mathrm{s}}=2.24 \times 10^{-6} \mathrm{~m}^{-1}$. It is seen that the model prediction fits the measured data very well, confirming the existence of the storage effect.

Concerning unconfined aquifers, a two-section characteristic for the MLST response (Fig. 7) may appear when the well is partially submerged with a thick filter pack and the aquifer is of relatively low hydraulic conductivity. "Partial submerged" is referred to as the condition where the water table is lower than the top of the well screen, so only the lower portion of the well is below the water table. The first section is much steeper than the second, reflecting a rapid drainage of the filter packer followed by a much slower response controlled by the hydraulic conductivity of the native aquifer (Bouwer 1989). Therefore, the data analysis excludes the use of the data points belonging to the first section, while drainage from the filter pack is taken into account by making use of an effective radius, $r_{\mathrm{e}}$. A modified graphic technique was proposed by Bouwer (1989) to determine $r_{e}$ and K. First a straight line is plotted passing through most data points of the second section, of which $\mathrm{T}_{0}$ is determined; $\mathrm{T}_{0}=8 \mathrm{~s}$, as indicated in Fig. 7. The test section length is $1_{s}=0.25 \mathrm{~m}$ and then the fitted line is extended to intersect the ordinate at $\mathrm{w}^{*}(=0.56)$, whereby the effective radius is calculated as $r_{e}=r_{w} / \sqrt{w^{*}}=0.068 m$. This $r_{e}$ is used in Eq. (8) to replace $r_{w}$ for the determination of K. Using the relationships in Appendix, $\mathrm{F}_{\mathrm{u}}$ is determined as 0.135 . Then $\mathrm{K}$ is calculated to be $4.85 \times 10^{-5} \mathrm{~m} \mathrm{~s}^{-1}$.

\section{A FIELD EXAMPLE FOR HIGH-RESOLUTION $\mathbf{K}(\mathbf{Z})$}

We now discuss a filed example which shows a highresolution $\mathrm{K}(\mathrm{z})$ determined with a series of MLSTs conducted in a 4 " well in a confined alluvial sandy aquifer. The aquifer consists of a silty layer from the ground surface to about $9 \mathrm{~m}$, and a sandy layer from $9 \mathrm{~m}$ to about $18.5 \mathrm{~m}$. Below $18.5 \mathrm{~m}$ to at least $20 \mathrm{~m}$ exists the bedrock. The well casing extends through the silt layer, while the well screen spans in the sandy layer. The water level was about $3.95 \mathrm{~m}$ below the ground surface, and thus the sandy layer is under a confined condition. A total of 28 MLSTs were accomplished at consecutive depths over the full screen length, $9.43 \mathrm{~m}$ using $1_{\mathrm{s}}=0.41 \mathrm{~m}$. The operational guideline stated above was applied to each MLST. At a few depths, two different $\mathrm{w}_{0}$, both less than $0.5 \mathrm{~m}$, were used to check the linearity of the responses.

Out of the 28 tests, there are 20 oscillatory responses and 8 nonoscillatory responses of the straight line characteristic. The estimates of $\mathrm{K}$ of the 20 oscillatory responses exceed $5 \times 10^{-4} \mathrm{~m} \mathrm{~s}^{-1}$, while the estimates of $\mathrm{K}$ of the 8 nonoscillatory responses are less than $2 \times 10^{-4} \mathrm{~m} \mathrm{~s}^{-1}$. As shown

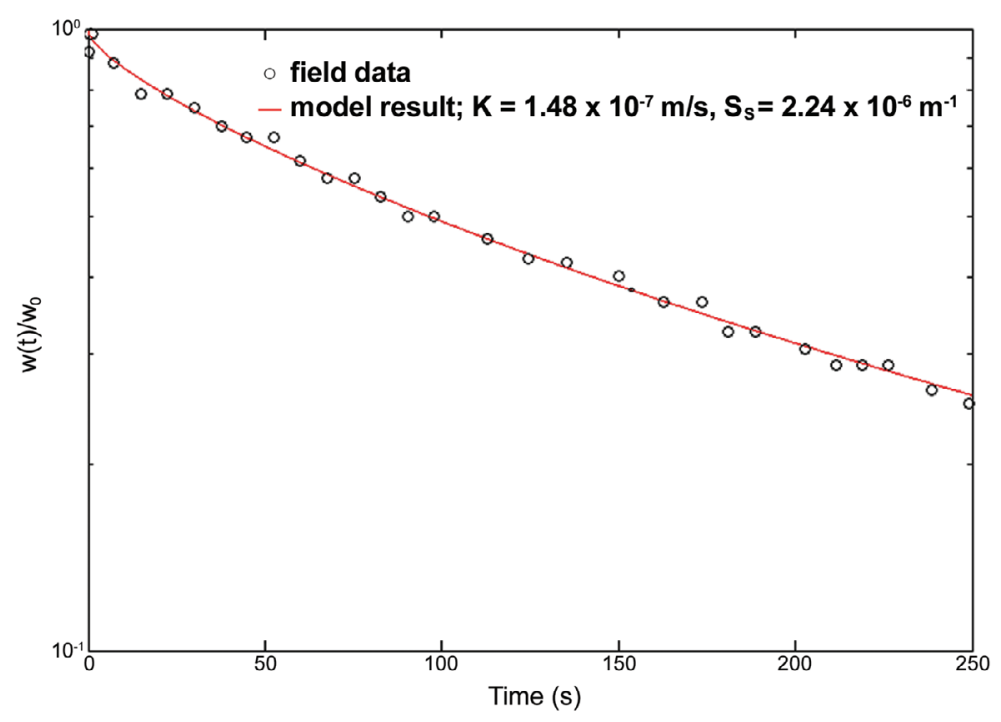

Fig. 6. The aquifer storage effect results in a concave downward trend for nonoscillatory response on semilog plot. 
in Fig. 8, the vertical distribution of $\mathrm{K}(\mathrm{z})$ varies with depth in an irregular way which corresponds well with the core sample description available to us, except for the depth from about 12 to $12.5 \mathrm{~m}$. The core sample description of this section is sandy gravel, while the two associated $\mathrm{K}$ values fall in the category of much finer, less permeable materials like silty sand. This inconsistence may be due to overlooking this relatively thin layer when classifying the core samples. Missing a thin layer of fine materials may cause significant misinterpretation of subsurface DNAPL movement (Bedient et al. 1999). DNAPL is the acronym for the "dense nonaqueous phase liquid," and chlorinated solvents are commonly discovered DNAPL at electronics manufactories.

\section{CONCLUSIONS AND SUGGESTIONS}

Aquifer heterogeneity $\mathrm{K}(\mathrm{x}, \mathrm{y}, \mathrm{z})$ significantly influences the groundwater movement and the associated solute transport. The characterization of aquifer heterogeneity is essential to the solutions of many practical and scientific

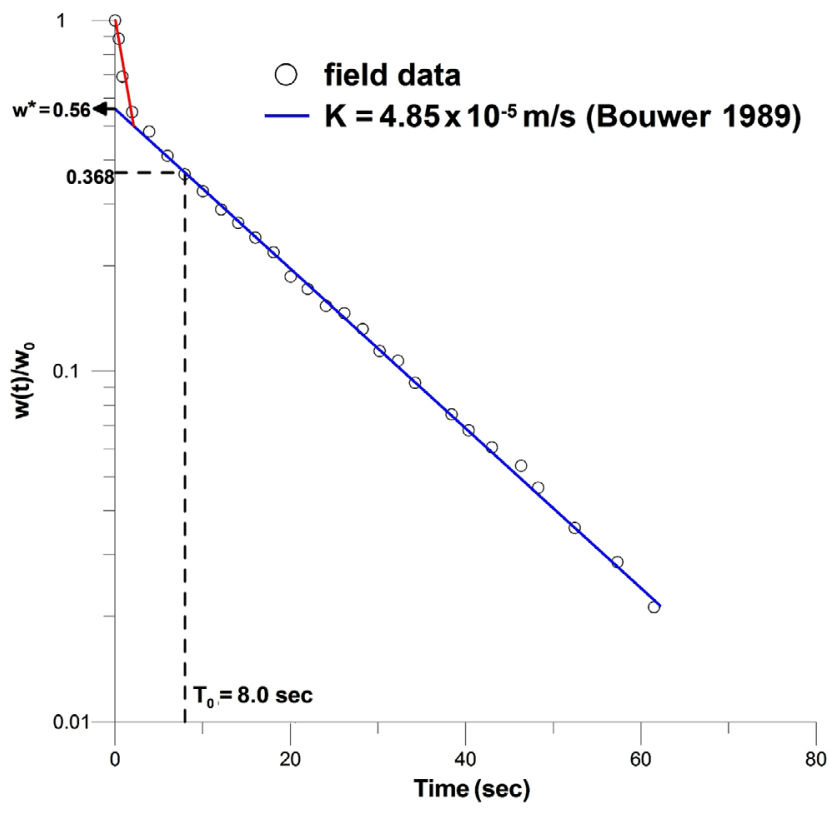

Fig. 7. Fast drainage from the filter pack results in a two-sectioned trend for nonoscillatory response in an unconfined aquifer.

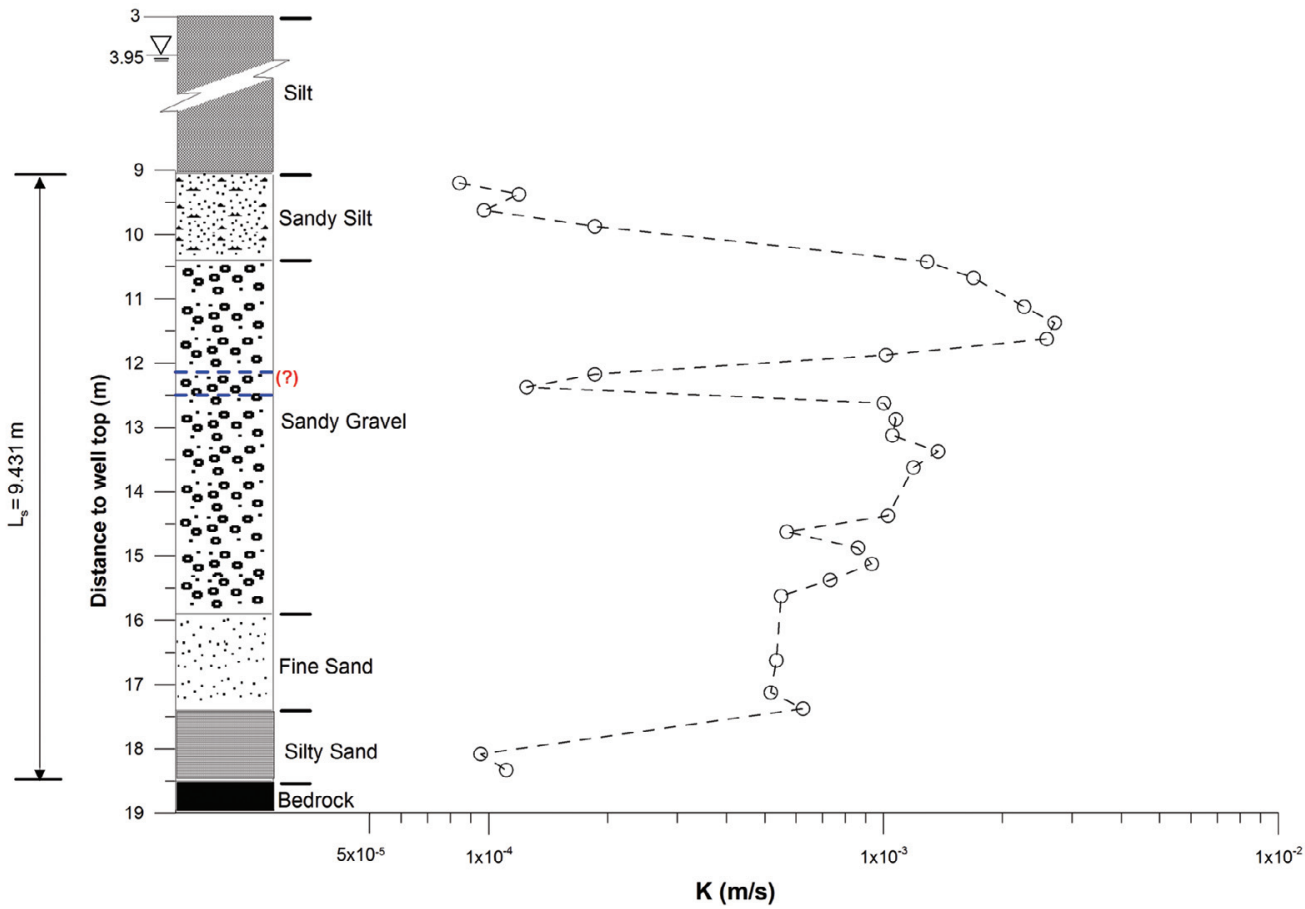

Fig. 8. A high-resolution $\mathrm{K}(\mathrm{z})$ acquired using a series of MLSTs with $\mathrm{l}_{\mathrm{s}}=0.41 \mathrm{~m}$ in a sandy aquifer.

groundwater problems. The multilevel slug test (MLST) is a useful technique, which determines a series of K estimates at depths of interest in a well by making use of a doublepacker system. The $\mathrm{K}(\mathrm{z})$ obtained manifests a vertical variation of hydraulic conductivity in the vicinity of the test well, and the combination of $\mathrm{K}(\mathrm{z})$ from different wells gives rise to a three-dimensional description of $\mathrm{K}(\mathrm{x}, \mathrm{y}, \mathrm{z})$.
The MLST response is rather sensitive to hydraulic conductivity variation. For example, it is oscillatory for highly permeable conditions $\left(\mathrm{K}>5 \times 10^{-4} \mathrm{~m} \mathrm{~s}^{-1}\right)$ while nonoscillatory for conditions of moderate to low hydraulic conductivity $\left(\mathrm{K}<5 \times 10^{-4} \mathrm{~m} \mathrm{~s}^{-1}\right)$. For an oscillatory response, the head measured is not necessarily the same as the water level variation, and the associated data analysis is rather complicated. 
To avoid such complication, an operational guideline for the MLST is recommended; that is, the pressure transducer is placed at about $0.5 \mathrm{~m}$ below the initial water level and the initial water displacement is set less than $0.5 \mathrm{~m}$. Under such a condition, the head measured is representative of the water level change and simple data analysis methods can be used. Some pertinent graphic data analysis methods are available and discussed for a spectrum of MLST responses frequently observed in confined or unconfined aquifers. Field examples indicate that the MLST is able to determine hydraulic conductivity of different depths and yield a high-resolution $\mathrm{K}(\mathrm{z})$ when a short test section length is used.

The MLST (and any other single-well hydraulic tests) is subject to the skin effect associated with the "damaged zone" in the close vicinity of the well. When the damaged zone is caused by drilling mud invasion, the hydraulic conductivity surrounding the well is reduced and the skin effect is called positive skin. When the damaged zone is created by overdevelopment of the well, the hydraulic conductivity surrounding the well is increased and the skin effect is called negative skin. For low-K conditions in either confined or unconfined aquifers, it is known that positive skin tends to cause an underestimation of $\mathrm{K}$ while negative skin causes an overestimation (Hyder et al. 1994; Hyder and Butler 1995; Yang and Gates 1997). For high-K conditions, the skin effect on the MLST is under continuing examination. Thus far, there is no method able to correct the error introduced by the skin effect to the estimate of K. Before such a method is available, it is suggested that either the well be thoroughly developed before the test in order to minimize the possible a skin effect, or no drilling mud is allowed to use while installing the well. and that using no drilling mud in installing the wells for hydraulic tests.

Acknowledgements Work reported in this article is partially supported by NSC96-2116-M-008-001-MY3 and EPA-99GA103-03-A236-14 of the Environmental Protection Administration of Taiwan, NSC99-2116-M-008-024 of the National Science Council of Taiwan.

\section{REFERENCES}

Alexander, M., S. J. Berg, and W. A. Illman, 2011: Field study of hydrogeologic characterization methods in a heterogeneous aquifer. Ground Water, 49, 365-382, doi: 10.1111/j.1745-6584.2010.00729.x. [Link]

Arnold, K. B. and F. J. Molz, 2000: In-well hydraulics of the electromagnetic borehole flowmeter: Further studies. Ground Water Monit. Remediat., 20, 52-55, doi: 10.1111/j.1745-6592.2000.tb00251.x. [Link]

Audouin, O. and J. Bodin, 2007: Analysis of slug-tests with high-frequency oscillations. J. Hydrol., 334, 282-289, doi: 10.1016/j.jhydrol.2006.10.009. [Link]

Audouin, O. and J. Bodin, 2008: Cross-borehole slug test analysis in a fractured limestone aquifer. J. Hydrol., 348, 510-523, doi: 10.1016/j.jhydrol.2007.10.021. [Link]

Beckie, R. and C. F. Harvey, 2002: What does a slug test measure: An investigation of instrument response and the effects of heterogeneity. Water Resour. Res., 38, 1290, doi: 10.1029/2001WR001072. [Link]

Bedient, P. B., H. S. Rifai, and C. J. Newell, 1999: Ground Water Contamination: Transport and Remediation, $2^{\text {nd }}$ Ed., Prentice Hall PTR, NJ, 604 pp.

Bianchi, M., C. Zheng, G. R. Tick, and S. M. Gorelick, 2011: Investigation of small-scale preferential flow with a forced-gradient tracer test. Ground Water, 49, 503514, doi: 10.1111/j.1745-6584.2010.00746.x. [Link]

Boman, G. K., F. J. Molz, and K. D. Boone, 1997: Borehole flowmeter application in fluvial sediments: Methodology, results, and assessment. Ground Water, 35, 443450, doi: 10.1111/j.1745-6584.1997.tb00104.x. [Link]

Bouwer, H., 1989: The Bouwer and Rice slug test - An update. Ground Water, 27, 304-309, doi: 10.1111/j.17456584.1989.tb00453.x. [Link]

Bouwer, H. and R. C. Rice, 1976: A slug test for determining hydraulic conductivity of unconfined aquifers with completely or partially penetrating wells. Water Resour. Res., 12, 423-428, doi: 10.1029/WR012i003p00423. [Link]

Butler, J. J. Jr., 1998: The Design, Performance, and Analysis of Slug Tests, Boca Raton, Lewis Publishers, Florida.

Butler, J. J. Jr. and X. Zhan, 2004: Hydraulic tests in highly permeable aquifers. Water Resour. Res., 40, W12402, doi: 10.1029/2003WR002998. [Link]

Butler, J. J. Jr., C. D. McElwee, and W. Liu, 1996: Improving the quality of parameter estimates obtained from slug tests. Ground Water, 34, 480-490, doi: 10.1111/j. 1745-6584.1996.tb02029.x. [Link]

Butler, J. J. Jr., E. J. Garnett, and J. M. Healey, 2003: Analysis of slug tests in formations of high hydraulic conductivity. Ground Water, 41, 620-631, doi: 10.1111/j. 1745-6584.2003.tb02400.x. [Link]

Butler, J. J. Jr., P. Dietrich, V. Wittig, and T. Christy, 2007: Characterizing hydraulic conductivity with the directpush permeameter. Ground Water, 45, 409-419, doi: 10.1111/j.1745-6584.2007.00300.x. [Link]

Chen, C. S., 2006: An analytic data analysis method for oscillatory slug tests. Ground Water, 44, 604-608, doi: 10.1111/j.1745-6584.2006.00202.x. [Link]

Chen, C. S., 2008: An analytical method of analysing the oscillatory pressure head measured at any depth in a well casing. Hydrol. Process., 22, 1119-1124, doi: 10. 1002/hyp.6666. [Link]

Chen, C.S. and C.R. Wu, 2006: Analysis of depth-dependent pressure head of slug tests in highly permeable aquifers. Ground Water, 44, 472-477, doi: 10.1111/j.17456584.2005.00152.x. [Link] 
Chirlin, G. R., 1989: A critique of the Hvorslev method for slug test analysis: The fully penetrating well. Ground Water Monit. Remediat., 9, 130-138, doi: 10.1111/j.17 45-6592.1989.tb01147.x. [Link]

Crisman, S. A., F. J. Molz, D. L. Dunn, and F. C. Sappington, 2001: Application procedures for the electromagnetic borehole flowmeter in shallow unconfined aquifers. Ground Water Monit. Remediat., 21, 96-100, doi: 10.1111/j.1745-6592.2001.tb00645.x. [Link]

Dietrich, P., J. J. Butler Jr., and K. Faiß, 2008: A rapid method for hydraulic profiling in unconsolidated formations. Ground Water, 46, 323-328, doi: 10.1111/j.17456584.2007.00377.x. [Link]

Freeze, R. A. and J. A. Cherry, 1979: Groundwater, Prentice-Hall, Englewood Cliffs, 604 pp.

Guyonnet, D., S. Mishra, and J. McCord, 1993: Evaluating the volume of porous medium investigated during slug tests. Ground Water, 31, 627-633, doi: 10.1111/j.17456584.1993.tb00596.x. [Link]

Haggerty, R. and S. M. Gorelick, 1995: Multiple-rate mass transfer for modeling diffusion and surface reactions in media with pore-scale heterogeneity. Water Resour. Res., 31, 2383-2400, doi: 10.1029/95WR10583. [Link]

Hvorslev, M. J., 1951: Time lag and soil permeability in ground-water observations, US Army Corps of Engineers, Waterways Experiment Station Bulletin No. 36, Mississippi, USA.

Hyder, Z. and J. J. Butler Jr., 1995: Slug tests in unconfined formations: An assessment of the Bouwer and Rice technique. Ground Water, 33, 16-22, doi: 10.1111/j.17 45-6584.1995.tb00258.x [Link]

Hyder, Z., J. J. Butler Jr., C. D. McElwee, and W. Liu, 1994: Slug tests in partially penetrating wells. Water Resour. Res., 30, 2945-2957, doi: 10.1029/94WR01670. [Link]

Liu, G., J. J. Butler Jr., G. C. Bohling, E. Reboulet, S. Knobbe, and D. W. Hyndman, 2009: A new method for high-resolution characterization of hydraulic conductivity. Water Resour. Res., 45, W08202, doi: 10.1029/ 2009WR008319. [Link]

Mathias, S. A. and A. P. Butler, 2006: An improvement on Hvorslev's shape factor. Géotechnique, 56, 705-706.

McElwee, C. D. and M. A. Zenner, 1998: A nonlinear model for analysis of slug-test data. Water Resour. Res., 34, 55-66.

McElwee, C. D., G. C. Bohling, and J. J. Butler Jr., 1995: Sensitivity analysis of slug tests. Part 1 . The slugged well. J. Hydrol., 164, 53-67, doi: 10.1016/0022-1694 (94)02568-V. [Link]

Ostendorf, D. W., D. J. DeGroot, P. J. Dunaj, and J. Jakubowski, 2005: A closed form slug test theory for high permeability aquifers. Ground Water, 43, 87-101, doi: 10.1111/j.1745-6584.2005.tb02288.x. [Link]

Paradis, D., R. Lefebvre, R. H. Morin, and E. Gloaguen,
2011: Permeability profiles in granular aquifers using flowmeters in direct-push wells. Ground Water, 49, 534-547, doi: 10.1111/j.1745-6584.2010.00761.x. [Link]

Prosser, D. W., 1981: A method of performing response tests on highly permeable aquifers. Ground Water, 19, 588592, doi: 10.1111/j.1745-6584.1981.tb03512.x. [Link]

Ratnam, S., K. Soga, and R. Whittle, 2001: Revisiting the Hvorslev's intake factors using the finite element method. Géotechnique, 51, 641-645.

Ross, H. C. and C. D. McElwee, 2007: Multi-level slug tests to measure 3-D hydraulic conductivity distributions. Nat. Resour. Res., 16, 67-79, doi: 10.1007/s11053-007 -9034-9. [Link]

Schumer, R., D. A. Benson, M. M. Meerschaert, and B. Baeumer, 2003: Fractal mobile/immobile solute transport. Water Resour. Res., 39, 1296, doi: 10.1029/2003 WR002141. [Link]

Sie, Y. C., 2009: Impact of the tested interval length of the multilevel slug test on the estimation of hydraulic conductivity. Master Thesis, National Central University, Jhongli, Taiwan. (in Chinese)

Springer, R. K., 1991: Application of an improved slug test analysis to the large-scale characterization of heterogeneity in a Cape Cod aquifer. Master Thesis, Department of Civil Engineering, Massachusetts Institute of Technology, Cambridge, Massachusetts, USA.

Springer, R. K. and L. W. Gelhar, 1991: Characterization of large-scale aquifer heterogeneity in glacial outwash by analysis of slug tests with oscillatory response, Cape Cod, Massachusetts. US Geological Survey Water-Resources Investigations Report 91-4034, 36-40.

van der Kamp, G., 1976: Determining aquifer transmissivity by means of well response tests: The underdamped case. Water Resour. Res., 12, 71-77, doi: 10.1029/WR 012i001p00071. [Link]

Yang, Y. J. and T. M. Gates, 1997: Wellbore skin effect in slug-test data analysis for low-permeability geologic materials. Ground Water, 35, 931-937, doi: 10.1111/ j.1745-6584.1997.tb00164.x. [Link]

Zemansky, G. M. and C. D. McElwee, 2005: High-resolution slug testing. Ground Water, 43, 222-230, doi: 10.1111/j.1745-6584.2005.0008.x. [Link]

Zenner, M. A., 2002: Analysis of slug tests in bypassed wells. J. Hydrol., 263, 72-91, doi: 10.1016/S0022-16 94(02)00048-3. [Link]

Zhang, Y., D. A. Benson, and B. Baeumer, 2008: Moment analysis for spatiotemporal fractional dispersion. Water Resour. Res., 44, W04424, doi: 10.1029/2007 WR006291. [Link]

Zhang, Y.,D. A. Benson, and D. M. Reeves, 2009: Time and space nonlocalities underlying fractional-derivative models: Distinction and literature review of field applications. Adv. Water Res., 32, 561-581. doi: 10.1016/j. 
advwatres.2009.01.008. [Link]

Zlotnik, V. A. and V. L. McGuire, 1998a: Multi-level slug tests in highly permeable formations: 1. Modification of the Springer-Gelhar (SG) model. J. Hydrol., 204, 271- 282, doi: 10.1016/S0022-1694(97)00128-5. [Link]

Zlotnik, V. A. and V. L. McGuire, 1998b: Multi-level slug tests in highly permeable formations: 2 . Hydraulic conductivity identification, method verification, and field applications. J. Hydrol., 204, 283-296, doi: 10.1016/S0 022-1694(97)00127-3. [Link]

Zlotnik V. A. and B. R. Zurbuchen, 1998: Dipole probe: Design and field applications of a single-borehole device for measurements of vertical variations of hydraulic conductivity. Ground Water, 36, 884-893, doi: 10. 1111/j.1745-6584.1998.tb02095.x. [Link]

Zlotnik V. A. and B. R. Zurbuchen, 2003: Field study of hydraulic conductivity in a heterogeneous aquifer: Comparison of single-borehole measurements using different instruments. Water Resour. Res., 39, 1101, doi: 10.1029/2002WR001415. [Link]

Zlotnik V. A., B. R. Zurbuchen, and T. Ptak, 1997: Applicability of the dipole flow test (DFT) and multi-level slug test (MLST) in highly conductive sediments: Horkheimer Insel Site, Germany. Eos, Trans., AGU, 77, Fall meeting, Suppl., F192.

Zlotnik V. A., B. R. Zurbuchen, and T. Ptak, 2001: The steady-state dipole-flow test for characterization of hydraulic conductivity statistics in a highly permeable aquifer: Horkheimer Insel Site, Germany. Ground Water, 39, 504-516, doi: 10.1111/j.1745-6584.2001.tb 02339.x. [Link]

Zlotnik, V. A, D. Goss, and G. M. Duffield, 2010: General steady-state shape factor for a partially penetrating well. Ground Water, 48, 111-116, doi: 10.1111/j.17456584.2009.00621.x. [Link]

Zurbuchen, B. A., V. A. Zoltnik, J. J. Butler Jr., J. Healy, and T. Ptak, 1998: Steady-state dipole flow tests in sand and gravel aquifers: Summary of field results. Geol. Soc. Am. Abstr. Programs, 30, A226.

Zurbuchen, B. R., V. A. Zlotnik, and J. J. Butler Jr., 2002: Dynamic interpretation of slug tests in highly permeable aquifers. Water Resour. Res., 38, 1025, doi: 10.10 29/2001WR000354. [Link]

\section{APPENDIX}

The following empirical relationships (Butler 1998) are used to calculate $\mathrm{F}_{\mathrm{u}}$ in Eq. (5). As shown in Fig. 2, $\mathrm{L}_{0}$ is the water depth above the top packer; other symbols are defined in the text.

$$
\begin{aligned}
& \ln \left(\frac{\mathrm{R}_{\mathrm{e}}}{\mathrm{r}_{\mathrm{w}}}\right)=\left[\frac{1.1}{\ln \left(\mathrm{L}_{0} / \mathrm{r}_{\mathrm{w}}+\alpha\right)}+\frac{\mathrm{A}}{\alpha}+\frac{\mathrm{B}}{\alpha} \ln \left(\frac{\mathrm{b}-\mathrm{L}_{0}}{\mathrm{r}_{\mathrm{w}}}-\alpha\right)\right]^{-1} \quad(\mathrm{~A} 1) \\
& \mathrm{A}= 1.472+3.537 \times 10^{-2} \alpha-8.148 \times 10^{-5} \alpha^{2}+1.028 \times 10^{-7} \alpha^{3} \\
&-6.484 \times 10^{-11} \alpha^{4}+1.573 \times 10^{-14} \alpha^{5} \\
& \mathrm{~B}= 0.237+5.151 \times 10^{-3} \alpha-2.682 \times 10^{-6} \alpha^{2}-3.491 \times 10^{-10} \alpha^{3} \\
&+ 4.738 \times 10^{-13} \alpha^{4}
\end{aligned}
$$

